Research Paper

\title{
The Clinical Usefulness of Measurement of Visceral Fat Area Using Multi-Frequency Bioimpedance: The Association with Cardiac and Renal Function In General Population with Relatively Normal Renal Function
}

\author{
Hye Eun Yoon ${ }^{1,2}$, Sang Su Choi ${ }^{1,2}$, Yaeni Kim¹,2, and Seok Joon Shin ${ }^{1,2}$ \\ 1. Division of Nephrology, Department of Internal Medicine, Incheon St. Mary's Hospital, Incheon, Korea: \\ 2. Division of Nephrology, Department of Internal Medicine, College of Medicine, The Catholic University of Korea, Seoul, Korea. \\ $\square$ Corresponding author: Seok Joon Shin, MD, PhD, Division of Nephrology, Department of Internal medicine, Incheon St. Mary's Hospital, College of \\ Medicine, The Catholic University of Korea, 56 Dongsu-ro, Bupyung-gu, Incheon, Republic of Korea, 21431 Tel: 82-32-280-5091, Fax: 82-32-280-5987 E-mail: \\ imkidney@catholic.ac.kr \\ (c) Ivyspring International Publisher. This is an open access article distributed under the terms of the Creative Commons Attribution (CC BY-NC) license \\ (https://creativecommons.org/licenses/by-nc/4.0/). See http://ivyspring.com/terms for full terms and conditions.
}

Received: 2017.06.09; Accepted: 2017.10.11; Published: 2017.11.02

\begin{abstract}
Background: This study was performed to determine the clinical usefulness of measurement of visceral fat area (VFA) using bioimpedance analysis in relation with left ventricular hypertrophy (LVH), diastolic dysfunction parameters, and decreased estimated glomerular filtration rate (eGFR).

Methods: A cross-sectional analysis was performed on 1028 patients with eGFR $\geq 60 \mathrm{ml} / \mathrm{min} / 1.73 \mathrm{~m}^{2}$, aged $40-64$ years, and who underwent routine health check-ups. Subjects were divided into tertiles based on their VFA. Associations of VFA with echocardiographic parameters and eGFR were evaluated.

Results: Across the VFA teriltes, there was a significant trend for increasing left ventricular mass index (LVMi), left atrial diameter (LAD), and ratio of early mitral inflow velocity to peak mitral annulus velocity (E/E' ratio) and that for decreasing ratio of early to late mitral inflow peak velocities (E/A ratio) and eGFR. In multivariate linear regression analysis, log-transformed VFA was significantly associated with increased LVMi, LAD, and E/E' ratio, and with decreased E/A ratio and eGFR. After adjustment for body mass index, log-transformed VFA remained as a significant determinant for E/A ratio.
\end{abstract}

Conclusion: VFA may be associated with LV structure and diastolic function, and decreased eGFR in middle-aged adults with normal or mildly impaired renal function.

Key words: visceral fat; bioimpedance analysis; glomerular filtration rate; echocardiography; left ventricular hypertrophy; diastolic dysfunction.

\section{Introduction}

Obesity is associated with increased left ventricular (LV) mass and impaired LV systolic and diastolic function, and elevated risk of cardiovascular disease (CVD) $[1,2]$. Obesity is also related with an increased risk of chronic kidney disease (CKD) in middle-aged and older adults [3,4]. Body mass index (BMI) is a well-known index for obesity, but it cannot discriminate between fat mass and lean body mass and does not account for fat distribution [5]. In normal aging, body fat undergoes redistribution, a disproportionate increase in visceral adiposity as opposed to subcutaenous adiposity [6]. Therefore, the single use of BMI as an index of obestiy may have limits to reflect the visceral adiposity. One of the tools to assess visceral adiposity is to measure visceral fat area (VFA). The gold standard method to measure VFA is computed tomography [7], however its use is limited as a screening tool for the general population.

Multi-frequency bioimpedance analysis (BIA) is a tool for measuring body composition, including lean mass, fat mass, and hydration status [8]. Advances in BIA techology have allowed VFA to be measured [9]. 
There are little data on the clinical usefulness of VFA measured by BIA in the general population, especially in middle-aged adults with relatively healthy renal function. This study was performed to evaluate the clinical significance of VFA measured by BIA in terms of LV structure and function and renal function, in middle-aged adults with relatively normal renal function.

\section{Methods}

\section{Study population}

We retrospectively recruited subjects who is from 40 to 64 years old and underwent health examinations at the Incheon St. Mary's Hospital Health Promotion Center as part of a voluntary medical check-up between January 2012 and December 2014. Subjects who had undergone biochemical studies, echocardiography and BIA were enrolled $(n=1032)$. We excluded individuals with an estimated glomerular filtration rate (eGFR) less than $60 \mathrm{ml} / \mathrm{min} / 1.73 \mathrm{~m}^{2}(\mathrm{n}=4)$. The eGFR was calculated using the abbreviated Modification of Diet in Renal Disease Study equation [10]. A total of 1028 subjects were included in the final analysis. This study was approved by the institutional review board of Incheon St. Mary's Hospital, Incheon, Korea.

\section{Data collection}

Medical history and social-behavioral information were collected through questionnaires. Physical examinations were performed by measuring height, weight, waist circumference (WC), and blood pressure (BP) according to standardized methods. During the measurements, the subjects were barefoot and wore light clothes. Before the measurement of BP, the subjects rested in a sitting position for 10 minutes. BMI was calculated by dividing weight by height squared $\left(\mathrm{kg} / \mathrm{m}^{2}\right)$. Blood samples were collected after an overnight fast. Fasting plasma glucose (FPG), and levels of fasting insulin, serum creatinine, total cholesterol (TC), triglyceride (TG), high-density lipoprotein-cholesterol (HDL-C), low-density lipoprotein-cholesterol (LDL-C), and C-reactive protein were measured. Subjects were considered to have hypertension if they had a systolic BP of 140 $\mathrm{mmHg}$ or greater and/or a diastolic BP of $90 \mathrm{~mm} \mathrm{Hg}$ or greater or if they were being treated for hypertension. Subjects were considered to have diabetes if he or she had a FPG of $\geq 126 \mathrm{mg} / \mathrm{dL}$ that was first detected in this examination, used an anti-diabetes medication, or was previously diagnosed with diabetes by a doctor. Dyslipidaemia was defined as a TG concentration of $150 \mathrm{mg} / \mathrm{dL}$ or greater or an LDL-C concentration of $100 \mathrm{mg} / \mathrm{dL}$ or greater and/or taking cholesterol-lowering medication. A history of CVD was defined as a previous stroke, angina, or myocardial infarction. VFA was measured using multi-frequency BIA (In-Body 720; Biospace, Seoul, Korea). The degree of insulin resistance assessed by homeostasis model assessment of insulin resistance (HOMA-IR) was calculated as follows: HOMA-IR = fasting insulin $(\mathrm{mU} / \mathrm{mL}) \times$ FPG $(\mathrm{mmol} / \mathrm{L}) / 22.5$ [11].

\section{Echocardiography}

A two-dimensional-guided M-mode echocardiography was performed by a cardiologist who was blind to the patient's clinical and laboratory data. M-mode measurements included left ventricular end-diastolic diameter (LVDd), left ventricular end-systolic diameter (LVDs), left ventricular posterior wall thickness (PWT), and interventricular septal thickness (IVST). Left ventricular mass (LVM) was calculated by means of the Devereux formula and indexed to height ${ }^{2.7}$ to determine the left ventricular mass index (LVMI), expressed in $\mathrm{g} / \mathrm{m}^{2.7}$ [12]. The criteria used to define left ventricular hypertrophy (LVH) was sex-specific LVM/ height ${ }^{2.7}$ partition values of $50 \mathrm{~g} / \mathrm{m}^{2.7}$ for men and $47 \mathrm{~g} / \mathrm{m}^{2.7}$ for women. Left ventricular ejection fraction (LVEF), and left atrial diameter (LAD) were determined from apical 2- and 4-chamber views by the Simpson's biplane formula, based on the recommendations of the American Society of Echocardiography [13]. To estimate diastolic function, mitral inflow velocities, and myocardial tissue velocities were recorded using pulsed wave Doppler and the tissue Doppler, respectively. From the mitral valve inflow velocity curve using pulsed wave Doppler, peak early diastolic flow velocity (MV-E), peak late diastolic flow velocity (MV-A), a ratio of $\mathrm{E}$ wave, and $\mathrm{A}$ wave (E/A ratio) were measured [14]. From tissue Doppler imaging, septal mitral annular early peak velocity $\left(E^{\prime}\right)$ was measured. A ratio of peak early transmitral flow velocity (E) to peak early diastolic mitral annular velocity (E/E' ratio), that is an estimate of left ventricular filling pressure, was also calculated [15]. High LAD was defined LAD > $35 \mathrm{~mm}$, High E/ $\mathrm{E}^{\prime}$ ratio as $\mathrm{E} / \mathrm{E}^{\prime}>7.9$ and low $\mathrm{E} / \mathrm{A}$ ratio as $\mathrm{E} / \mathrm{A}$ ratio < 10.5 , according to the median values.

\section{Statistical analysis}

Subjects were divided into tertiles according to VFA values: tertile $1\left(\leq 102.6 \mathrm{~cm}^{2}\right)$, tertile 2 (102.6-127.1 $\left.\mathrm{cm}^{2}\right)$, and tertile $3\left(>127.1 \mathrm{~cm}^{2}\right)$. Differences in the baseline characteristics between the tertiles were evaluated. Continuous data were expressed as the mean \pm SD or as the median with interquartile range ( $25^{\text {th }}$ to $75^{\text {th }}$ percentile) in case of skewed distribution, and were compared using one-way ANOVA or the 
Kruskal-Wallis test, as appropriate. Categorical data were expressed as numbers (percentage) and compared using the chi-squared test. Pearson correlation analysis was performed to examine the association between log-transformed VFA (logVFA) and various parameters. Multivariate linear regression analysis was used to assess the association of $\operatorname{logVFA}$ with eGFR, and echocardiographic parameters after adjusting for confounding factors. $P$ values of $<0.05$ were considered statistically significant.

\section{Results}

\section{Baseline characteristics according to the VFA tertiles}

The clinical characteristics of 1028 subjects stratified by VFA tertiles are shown in Table 1. Subjects in the highest VFA tertile were more likely to be older, men, smokers, and those with BMI $>25 \mathrm{~kg} / \mathrm{m}^{2}$ and to have diabetes, hypertension, or dyslipidaemia. The highest VFA tertile group had higher systolic and diastolic BP, WC, and BMI levels, than the middle and lowest VFA teritle groups. Subjects in the highest VFA tertile had higher FPG, HOMA-IR, TC, TG, LDL-C, and C-reactive protein levels, and lower HDL-C and eGFR levels compared with those in the middle and lowest VFA tertile groups.

\section{Association between logVFA values and clinical and echocardiographic parameters}

LogVFA was positively correlated with age and levels of systolic and diastolic BP, WC, BMI, FPG, HOMA-IR, TC, TG, LDL-C, and C-reactive protein, $\mathrm{LVMi}, \mathrm{LAD}$, and $\mathrm{E} / \mathrm{E}^{\prime}$ ratio, while it was negatively correlated with HDL-C level, eGFR, and E/A ratio. After age- and sex-adjustment, $\log V F A$ was positively correlated with systolic and diastolic BP, WC, BMI, FPG, HOMA-IR, TC, TG, LDL-C, C-reactive protein, $\mathrm{LVMi}, \mathrm{LAD}$, and $\mathrm{E} / \mathrm{E}^{\prime}$ ratio, and negatively correlated with HDL-C and E/A ratio (Table 2).

\section{Association between VFA tertiles and LVH, high LAD, high E/E' ratio, low E/A ratio and eGFR $<90 \mathrm{ml} / \mathrm{min} / 1.73 \mathrm{~m}^{2}$}

Table 3 shows the comparisons of LVMi, LAD, $\mathrm{E} / \mathrm{E}^{\prime}$ and $\mathrm{E} / \mathrm{A}$ ratios, and eGFR, and the prevalence of $\mathrm{LVH}$, high $\mathrm{LAD}$, high $\mathrm{E} / \mathrm{E}^{\prime}$ ratio, low $\mathrm{E} / \mathrm{A}$ ratio and eGFR $<90 \mathrm{ml} / \mathrm{min} / 1.73 \mathrm{~m}^{2}$. The levels of LVMi, LAD, and $\mathrm{E} / \mathrm{E}^{\prime}$ ratio increased as the VFA levels increased. The prevalence of $\mathrm{LVH}$, high $\mathrm{LAD}$, and high $\mathrm{E} / \mathrm{E}^{\prime}$ ratio also increased as the VFA levels increased. The levels of E/A ratio and eGFR decreased, and the prevalence of low $\mathrm{E} / \mathrm{A}$ ratio significantly increased as the VFA levels increased. However, the prevalence of eGFR $<90 \mathrm{ml} / \mathrm{min} / 1.73 \mathrm{~m}^{2}$ was not different between VFA tertiles.

Table 1. Clinical characteristics of subjects.

\begin{tabular}{|c|c|c|c|c|}
\hline & VFA & & & \\
\hline & $\begin{array}{l}\text { Tertile } 1 \\
\leq 102.6 \mathrm{~cm}^{2}\end{array}$ & $\begin{array}{l}\text { Tertile } 2 \\
102.6-127.1 \mathrm{~cm}^{2}\end{array}$ & $\begin{array}{l}\text { Tertile } 3 \\
>127.1 \mathrm{~cm}^{2}\end{array}$ & $P$ \\
\hline $\mathrm{n}$ & 344 & 342 & 342 & \\
\hline Age (years) & $50.6 \pm 6.1$ & $52.1 \pm 6.3$ & $53.6 \pm 6.1$ & $<0.001$ \\
\hline Male (\%) & $215(62.5)$ & $259(75.7)$ & $298(87.1)$ & $<0.001$ \\
\hline Current smokers (\%) & $109(31.7)$ & $102(29.8)$ & $136(39.8)$ & 0.014 \\
\hline Alcohol drinking (\%) & $222(64.5)$ & $242(70.8)$ & $249(72.8)$ & 0.05 \\
\hline Diabetes (\%) & $32(9.3)$ & $54(15.8)$ & $67(19.6)$ & 0.001 \\
\hline Hypertension (\%) & $73(21.2)$ & $97(28.4)$ & $177(51.8)$ & $<0.001$ \\
\hline Dyslipidaemia (\%) & $300(87.2)$ & $316(92.4)$ & $320(93.6)$ & 0.008 \\
\hline CVD $(\%)$ & $14(4.1)$ & $20(5.8)$ & $17(5.0)$ & 0.563 \\
\hline Systolic BP (mmHg) & $115.5 \pm 14.2$ & $120.2 \pm 14.0$ & $125.4 \pm 15.0$ & $<0.001$ \\
\hline Diastolic BP (mmHg) & $75.2 \pm 10.7$ & $78.5 \pm 10.6$ & $82.2 \pm 9.9$ & $<0.001$ \\
\hline $\mathrm{WC}(\mathrm{cm})$ & $76.0 \pm 6.7$ & $83.1 \pm 6.3$ & $91.5 \pm 7.3$ & $<0.001$ \\
\hline BMI $\left(\mathrm{kg} / \mathrm{m}^{2}\right)$ & $22.2 \pm 2.2$ & $24.8 \pm 2.1$ & $27.5 \pm 2.7$ & $<0.001$ \\
\hline BMI <25 (\%) & $310(90.1)$ & $191(55.8)$ & $57(16.7)$ & $<0.001$ \\
\hline $\mathrm{BMI} \geq 25(\%)$ & $34(9.9)$ & $151(44.2)$ & $285(83.3)$ & \\
\hline FPG $(\mathrm{mg} / \mathrm{dL})$ & $99.0 \pm 24.0$ & $104.8 \pm 27.3$ & $112.2 \pm 35.7$ & $<0.001$ \\
\hline HOMA-IR & $1.1(0.8-1.6)$ & $1.6(1.1-2.3)$ & $2.3(1.7-3.4)$ & $<0.001$ \\
\hline $\mathrm{TC}(\mathrm{mg} / \mathrm{dL})$ & $196.0 \pm 36.3$ & $203.5 \pm 38.3$ & $199.6 \pm 38.4$ & 0.033 \\
\hline $\mathrm{TG}(\mathrm{mg} / \mathrm{dL})$ & $103.0(75.0-144.8)$ & $140.5(101.8-190.3)$ & $165.0(118.0-227.3)$ & $<0.001$ \\
\hline HDL-C (mg/dL) & $53.9 \pm 11.8$ & $50.0 \pm 11.4$ & $47.2 \pm 9.6$ & $<0.001$ \\
\hline LDL-C (mg/dL) & $126.3 \pm 28.4$ & $134.7 \pm 30.0$ & $132.2 \pm 31.4$ & 0.001 \\
\hline C-reactive protein $(\mathrm{mg} / \mathrm{L})$ & $0.38(0.21-0.83)$ & $0.63(0.34-1.17)$ & $0.93(0.54-1.82)$ & $<0.001$ \\
\hline $\mathrm{eGFR}\left(\mathrm{ml} / \mathrm{min} / 1.73 \mathrm{~m}^{2}\right)$ & $107.9(93.8-115.4)$ & $103.4(92.1-112.2)$ & $105.5(91.7-115.5)$ & 0.008 \\
\hline
\end{tabular}

CVD, cardiovascular disease; BP, blood pressure; WC, waist circumference; BMI, body mass index; FPG, fasting plasma glucose; HOMA-IR, homeostasis model assessment of insulin resistance; TC, total cholesterol; TG, triglyceride; HDL-C, high-density lipoprotein-cholesterol; LDL-C, low-density lipoprotein-cholesterol; eGFR, estimated glomerular filtration rate 
Table 2. Correlations between log-transformed VFA and clinical and echocardiographic parameters

\begin{tabular}{|c|c|c|c|c|}
\hline & \multicolumn{2}{|c|}{ Unadjusted } & \multicolumn{2}{|c|}{ Age- and sex- adjusted } \\
\hline & $r$ & $P$ & $r$ & $P$ \\
\hline Age & 0.19 & $<0.001$ & - & - \\
\hline Systolic BP & 0.28 & $<0.001$ & 0.27 & $<0.001$ \\
\hline Diastolic BP & 0.28 & $<0.001$ & 0.25 & $<0.001$ \\
\hline WC & 0.70 & $<0.001$ & 0.71 & $<0.001$ \\
\hline BMI & 0.70 & $<0.001$ & 0.72 & $<0.001$ \\
\hline FPG & 0.20 & $<0.001$ & 0.15 & $<0.001$ \\
\hline HOMA-IR & 0.72 & $<0.001$ & 0.44 & $<0.001$ \\
\hline TC & 0.07 & 0.021 & 0.10 & 0.001 \\
\hline $\mathrm{TG}^{\mathrm{a}}$ & 0.36 & $<0.001$ & 0.35 & $<0.001$ \\
\hline HDL-C & -0.27 & $<0.001$ & -0.23 & $<0.001$ \\
\hline LDL-C & 0.12 & 0.003 & 0.15 & $<0.001$ \\
\hline C-reactive protein & 0.36 & $<0.001$ & 0.07 & 0.025 \\
\hline eGFR & -0.08 & 0.014 & -0.06 & 0.066 \\
\hline LVMi & 0.21 & $<0.001$ & 0.20 & $<0.001$ \\
\hline LVEF & 0.007 & 0.816 & 0.02 & 0.449 \\
\hline LAD & 0.40 & $<0.001$ & 0.37 & $<0.001$ \\
\hline $\mathrm{E} / \mathrm{A}$ ratio & -0.29 & $<0.001$ & -0.23 & $<0.001$ \\
\hline $\mathrm{E} / \mathrm{E}^{\prime}$ ratio & 0.17 & $<0.001$ & 0.15 & $<0.001$ \\
\hline
\end{tabular}

BP, blood pressure; WC, waist circumference; BMI, body mass index; FPG, fasting plasma glucose; HOMA-IR, homeostasis model assessment of insulin resistance; TC, total cholesterol; TG, triglyceride; HDL-C, high-density lipoprotein-cholesterol; LDL-C, low-density lipoprotein-cholesterol; eGFR, estimated glomerular filtration rate; LVMi, left ventricular mass index; LVEF, left ventricular ejection fraction; LAD, left atrial diameter; E/A ratio, ratio of early to late mitral inflow peak velocities; E/ E' ratio, ratio of early mitral inflow velocity to peak mitral annulus velocity. aTested by log-transformed value.

Table 3. Mean or median levels of LVMi, LAD, E/E' and E/A ratio and eGFR and prevalence of LVH, high LAD, high E/E', low E/A ratio and eGFR $<90 \mathrm{ml} / \mathrm{min} / 1.73 \mathrm{~m}^{2}$ according to VFA tertiles.

\begin{tabular}{|c|c|c|c|c|}
\hline & \multicolumn{3}{|l|}{ VFA } & \multirow[t]{2}{*}{$P$} \\
\hline & Tertile 1 & Tertile 2 & Tertile 3 & \\
\hline LVMi $\left(\mathrm{g} / \mathrm{m}^{2}\right)$ & $37.4 \pm 7.3$ & $39.1 \pm 7.6$ & $44.3 \pm 18.1$ & $<0.001$ \\
\hline Prevalence LVH (n) & $5.2 \%(18)$ & $7.6 \%(26)$ & $21.1 \%(72)$ & $<0.001$ \\
\hline $\mathrm{LAD}(\mathrm{mm})$ & $33.0 \pm 4.6$ & $35.3 \pm 4.6$ & $37.9 \pm 4.9$ & $<0.001$ \\
\hline Prevalence of high LAD (n) & $25.3 \%(87)$ & $48.5 \%(166)$ & $68.7 \%(235)$ & $<0.001$ \\
\hline $\mathrm{E} / \mathrm{E}^{\prime}$ ratio & $7.7 \pm 2.3$ & $8.1 \pm 2.0$ & $8.6 \pm 2.3$ & $<0.001$ \\
\hline Prevalence of high E/E' ratio (n) & $39.0 \%(134)$ & $45.9 \%(157)$ & $57.0 \%(195)$ & $<0.001$ \\
\hline $\mathrm{E} / \mathrm{A}$ ratio & $1.19 \pm 0.37$ & $1.09 \pm 0.32$ & $0.97 \pm 0.25$ & $<0.001$ \\
\hline Prevalence of low E/A ratio (n) & $35.8 \%(123)$ & $48.2 \%(165)$ & $63.5 \%(217)$ & $<0.001$ \\
\hline eGFR $\left(\mathrm{ml} / \mathrm{min} / 1.73 \mathrm{~m}^{2}\right)$ & $107.9(93.8-115.4)$ & $103.4(92.1-112.2)$ & $105.5(91.7-115.5)$ & 0.008 \\
\hline Prevalence of eGFR $<90 \mathrm{ml} / \mathrm{min} / 1.73 \mathrm{~m}^{2}$ & $14.2 \%(49)$ & $19.6 \%(67)$ & $19.3 \%(66)$ & 0.119 \\
\hline
\end{tabular}

LVMi, left ventricular mass index; LVEF, left ventricular ejection fraction; LAD, left atrial diameter; E/ $\mathrm{E}^{\prime}$ ratio, ratio of early mitral inflow velocity to peak mitral annulus velocity; E/A ratio, ratio of early to late mitral inflow peak velocities; eGFR, estimated glomerular filtration rate.

Table 4. Association between logVFA levels and LVMi, LAD, E/E' ratio, E/A ratio and eGFR.

\begin{tabular}{|c|c|c|c|c|c|c|c|c|c|c|}
\hline & LVMi & & LAD & & $\mathrm{E} / \mathrm{E}^{\prime}$ ratio & & E/A ratio & & eGFR & \\
\hline & B (95\% CI) & $P$ & B $(95 \% \mathrm{CI})$ & $P$ & B $(95 \%$ CI $)$ & $P$ & $B(95 \% \mathrm{CI})$ & $P$ & B $(95 \%$ CI $)$ & $P$ \\
\hline \multicolumn{11}{|l|}{ Model 1} \\
\hline $\log V F A$ & $\begin{array}{l}13.88 \\
(8.11,19.65)\end{array}$ & $<0.001$ & $\begin{array}{l}12.37 \\
(10.19,14.55)\end{array}$ & $<0.001$ & $\begin{array}{l}1.94 \\
(0.91,2.96)\end{array}$ & $<0.001$ & $\begin{array}{l}-0.34 \\
(-0.48,-0.21)\end{array}$ & $<0.001$ & $\begin{array}{l}-10.65 \\
(-20.43,-0.86)\end{array}$ & 0.033 \\
\hline \multicolumn{11}{|l|}{ Model 2} \\
\hline $\log V F A$ & $\begin{array}{l}5.04 \\
(-1.58,11.67)\end{array}$ & 0.136 & $\begin{array}{l}7.12 \\
(4.66,9.58)\end{array}$ & $<0.001$ & $\begin{array}{l}0.84 \\
(-0.35,2.03)\end{array}$ & 0.165 & $\begin{array}{l}-0.27 \\
(-0.42,-0.12)\end{array}$ & 0.001 & $\begin{array}{l}-9.73 \\
(-21.13,1.66)\end{array}$ & 0.094 \\
\hline \multicolumn{11}{|l|}{ Model 3} \\
\hline $\log V F A$ & $\begin{array}{l}-7.19 \\
(-14.89,0.51)\end{array}$ & 0.067 & $\begin{array}{l}1.33 \\
(-1.51,4.16)\end{array}$ & 0.359 & $\begin{array}{l}0.08 \\
(-1.33,1.48)\end{array}$ & 0.913 & $\begin{array}{l}-0.22 \\
(-0.40,-0.03)\end{array}$ & 0.02 & $\begin{array}{l}-2.64 \\
(-16.10,10.82)\end{array}$ & 0.700 \\
\hline
\end{tabular}

Model 1: Adjusted for age, sex, diabetes, systolic BP, diastolic BP, smoking, alcohol drinking, dyslipidaemia, and history of CVD Model 2: Adjusted for model $1+$ BMI as a categorical variable (BMI $<25 \mathrm{~kg} / \mathrm{m}^{2}$ vs. BMI $\geq 25 \mathrm{~kg} / \mathrm{m}^{2}$ ) Model 3: Adjusted for model $1+\mathrm{BMI}$ as a continuous variable

\section{Association between logVFA and LVMi, LAD, E/E' ratio, E/A ratio and $\mathrm{EGFR}$}

Multivariate linear regression analysis was performed to examine the continuous association between $\log$ VFA with $\mathrm{LVMi}, \mathrm{LAD}, \mathrm{E} / \mathrm{E}^{\prime}$ ratio, E/A ratio, and eGFR (Table 4). LogVFA was linearly associated with LVMi $(ß=13.88, P<0.001)$, LAD $(ß=$
12.37, $P<0.001)$, E/E'ratio $(B=1.94, P<0.001)$, E/A ratio $(B=-0.34, P<0.001)$, and eGFR $(B=-10.65, P=$ 0.033 ) in model 1 . In model 2 , which included BMI as a categorical variable, the association remained significant for $\operatorname{LAD}(B=7.12, P<0.001)$ and $\mathrm{E} / \mathrm{A}$ ratio $(B=-0.27, P=0.001)$. In model 3 , which included BMI as a continuous variable, the association remained significant only for $\mathrm{E} / \mathrm{A}$ ratio $(B=-0.22, P=0.02)$. In 
model 3, BMI was a significant determinant for LVMi $(B=1.33, P<0.001)$, LAD $(B=0.70, P<0.001), \mathrm{E} / \mathrm{E}^{\prime}$ ratio $(B=0.12, P<0.001)$ and $E / A$ ratio $(B=-0.008, P=$ $0.05)$.

\section{Discussion}

The results of our study showed that VFA measured by BIA was associated with LV structure and diastolic function and renal function in middle-aged adults. VFA was associated with increased LV mass, $L A D$, and $E / E^{\prime}$ ratio and decreased $\mathrm{E} / \mathrm{A}$ ratio and eGFR. In multivariate linear regression analysis including $\mathrm{BMI}$, the association remained significant for E/A ratio. These findings suggest that measurement of VFA using BIA may be useful to identify milddle-aged adults with increased risks of cardiac or renal diseases, especially for detecting changes in mitral valve flow velocities.

Visceral obesity is known to increase in normal aging [6], and directly affects inflammation and insulin resistance [16]. The visceral fat component is metabolically active and regulates adipokines and cytokines which are associated with increased cardiometabolic risk, including leptin, adiponectin, plasminogen activator-1 and vascular endothelial growth factor [17-20]. In our study, subjects in the highest VFA tertile group were more likely to be older and smoker and to have diabetes, hypertension, or dyslipidaemia. Their systolic and diastolic BP, WC, BMI, FPG, lipid levels, and C-reactive protein were higher and they had higher insulin resistance. The correlation analyses also showed positive associations of logVFA with levels of systolic and diastolic BP, WC, BMI, FPG, HOMA-IR, lipids, and C-reactive protein after age- and sex-adjustment. These findings support that VFA is related with hypertension, metabolic abnormalities and inflammation, all of which increase the risk of CVD.

Previous reports showed the effect of obesity on LV structure and function based on BMI [21, 22]. Visceral adiposity measured by computed tomography was associated with increased LAD and LVMi and decreased LV systolic and diastolic function [23-25], while subcutaneous fat did not [23]. The results of our study extend these findings to a younger population (mean age 52 years). The VFA measured by BIA was associated with increased $\mathrm{LVMi}, \mathrm{LAD}$, and $\mathrm{E} / \mathrm{E}^{\prime}$ ratio and decreased $\mathrm{E} / \mathrm{A}$ ratio. Especially, the association of VFA with E/A ratio remained significant even after adjusting for BMI. Animal studies showed that accumulation of lipids in the myocardium is related with cardiac dysfunction in obese rats [26], and that therapeutic interventions to reduce visceral adiposity improved cardiac hypertrophy in Western diet-fed mice [27]. In human,
TG accumulation in the myocardium increased with aging and was independently associated with LV diastolic dysfunction [28]. Therefore, myocardial accumulation of lipids may be a potential mechanism by which increased visceral adiposity mediates structural and functional change of LV. In our study, the VFA level was not a better determinant for LVMi, $\mathrm{LAD}$, and $\mathrm{E} / \mathrm{E}^{\prime}$ ratio than $\mathrm{BMI}$. However, VFA showed a closer relationship with E/A ratio than BMI did. These findings suggest that measurement of VFA using BIA may be useful to detect early changes in mitral valve flow velocities.

There are previous reports on the association between obesity and renal function. Obesity measurements including BMI, WC and fat mass measured by BIA were associated with increased risk of rapid eGFR loss and the strongest OR for rapid eGFR loss was observed when baseline eGFR was $<60$ $\mathrm{ml} / \mathrm{min} / 1.73 \mathrm{~m}^{2}$ [4]. In contrast, there are reports showing that obesity, defined by the BMI, was not per se a risk of CKD (eGFR $\left.<60 \mathrm{ml} / \mathrm{min} / 1.73 \mathrm{~m}^{2}\right)[29,30]$, but a metabolically abnormal obesity is a risk of CKD [30]. Since BMI cannot discriminate between fat mass, lean body mass and visceral adiposity [5], it cannot represent the metabolical abnormality or inflammation. A recent cross-sectional study demonstrated that VFA measured by BIA was associated with CKD (eGFR $<60 \mathrm{ml} / \mathrm{min} / 1.73 \mathrm{~m}^{2}$ ) [31]. The authors reported that the prevalence of CKD ranged from $6.9 \%$ to $25.2 \%$ according to VFA tertile groups. Our study also evaluated the association between VFA level and eGFR. However, the difference was that the study population of this study was limited to adults with eGFR $\geq 60 \mathrm{ml} / \mathrm{min} / 1.73 \mathrm{~m}^{2}$, those who have relatively healthy renal function. In this study, the eGFR levels decreased as the VFA tertile increased, and the logVFA showed a negative relationship with eGFR after adjustment for age, sex, diabetes, systolic and diastolic BP, smoking, alcohol drinking, dyslipidaemia, and history of CVD. However, when BMI was included in the multivariate analysis, neither logVFA nor BMI was a significant determinant for eGFR. We speculate that the cross-sectional design of our study had limits to show the effect of VFA on renal function in middle-aged adults with relatively healthy renal function.

Recently it was published that visceral adiposity measured by computed tomography was a risk factor for renal function decline in elderly subjects without baseline CKD [32]. Multiple mechanisms underlie the association between obesity and CKD. Visceral adiposity is involved in inflammation, oxidative stress, and insulin resistance [33], and leads to the activation of the sympathetic nervous system and renin-angiotensin systems, lipid deposition and 
increased sodium absorption in the kidneys resulting in hypertension and decline in renal function [34]. It was also demonstrated that hypertension mediates the association between obesity and CKD development [35]. In our study, VFA was related with hypertension, dyslipidaemia, insulin resistance, and inflammation. Therefore the association between VFA and eGFR may be mediated by metabolic abnormality, hypertension and inflammation. These findings suggest that VFA can be a modifiable risk factor for the decline of eGFR in subjects with relatively healthy renal function.

Strengths of our study include a specified population, middle-aged adults with eGFR $\geq 60$ $\mathrm{ml} / \mathrm{min} / 1.73 \mathrm{~m}^{2}$, and a simultaneous assessment of LV structure and function and renal function. However our study has several limitations. First, it was a retrospective, cross-sectional analysis from a single center. Second, the causal relationship between VFA and cardiac and renal function could not be determined. Third, the effect of specific medications could not be assessed as the medical and social-behavioral information were collected through questionnaires. Fourth, the advantage of VFA over BMI for predicting LV structural and functional changes and renal function was not clearly shown from our study.

In conclusion, high VFA levels were associated with high levels of LVMi, LAD, and $E / E^{\prime}$ ratio and low levels of E/A ratio and eGFR. These findings suggest that VFA may be associated with the development of $\mathrm{LVH}$, diastolic dysfunction, and decline of eGFR in middle-aged adults with normal or mildly impaired renal function. Measurement of VFA using BIA could be useful to identify subjects at increased risk of cardiac disease or CKD. Further research is needed to determine the role of VFA on cardiac and renal diseases.

\section{Acknowledgement}

This research was supported by the Basic Science Research Program through the National Research Foundation of Korea (NRF) funded by the Ministry of Science, ICT and future Planning (2014R1A1A3A04050919).

\section{Competing Interests}

The authors have declared that no competing interest exists.

\section{References}

1. Jee SH, Sull JW, Park J, et al. Body-mass index and mortality in Korean men and women. N Engl J Med. 2006; 355: 779-87.

2. Lavie CJ, Ventura HO, Messerli FH. Left ventricular hypertrophy. Its relationship to obesity and hypertension. Postgrad Med. 1992; 91: 131-2, 5-8, 41-3.
3. Kramer $\mathrm{H}$, Luke A, Bidani A, Cao G, Cooper R, McGee D, Obesity and prevalent and incident CKD: the Hypertension Detection and Follow-Up Program. Am J Kidney Dis. 2005; 46: 587-94.

4. de Boer $\mathrm{IH}$, Katz R, Fried LF, et al. Obesity and change in estimated GFR among older adults. Am J Kidney Dis. 2009; 54: 1043-51.

5. Heymsfield SB, Cefalu WT. Does body mass index adequately convey a patient's mortality risk? Jama. 2013; 309: 87-8.

6. Hughes VA, Frontera WR, Roubenoff R, Evans WJ, Singh MA. Longitudinal changes in body composition in older men and women: role of body weight change and physical activity. Am J Clin Nutr. 2002; 76: 473-81.

7. Micklesfield LK, Evans J, Norris SA, et al. Dual-energy X-ray absorptiometry and anthropometric estimates of visceral fat in Black and White South African Women. Obesity (Silver Spring). 2010; 18: 619-24.

8. Jackson AS, Pollock ML, Graves JE, Mahar MT. Reliability and validity of bioelectrical impedance in determining body composition. J Appl Physiol (1985). 1988; 64: 529-34

9. Ogawa H, Fujitani $K$, Tsujinaka $T$, et al. InBody 720 as a new method of evaluating visceral obesity. Hepatogastroenterology. 2011; 58: 42-4.

10. Levey AS, Bosch JP, Lewis JB, Greene T, Rogers N, Roth D. A more accurate method to estimate glomerular filtration rate from serum creatinine: a new prediction equation. Modification of Diet in Renal Disease Study Group. Ann Intern Med. 1999; 130: 461-70.

11. Bonora E, Kiechl S, Willeit J, et al. Prevalence of insulin resistance in metabolic disorders: the Bruneck Study. Diabetes. 1998; 47: 1643-9.

12. de Simone G, Devereux RB, Roman MJ, Alderman MH, Laragh JH. Relation of obesity and gender to left ventricular hypertrophy in normotensive and hypertensive adults. Hypertension. 1994; 23: 600-6.

13. Schiller NB, Shah PM, Crawford M, et al. Recommendations for quantitation of the left ventricle by two-dimensional echocardiography. American Society of Echocardiography Committee on Standards, Subcommittee on Quantitation of Two-Dimensional Echocardiograms. J Am Soc Echocardiogr. 1989; 2: 358-67.

14. Rakowski H, Appleton C, Chan KL, et al. Canadian consensus recommendations for the measurement and reporting of diastolic dysfunction by echocardiography: from the Investigators of Consensus on Diastolic Dysfunction by Echocardiography. J Am Soc Echocardiogr. 1996; 9: 736-60.

15. Nagueh SF, Middleton KJ, Kopelen HA, Zoghbi WA, Quinones MA. Doppler tissue imaging: a noninvasive technique for evaluation of left ventricular relaxation and estimation of filling pressures. J Am Coll Cardiol. 1997; 30: 1527-33.

16. Schrager MA, Metter EJ, Simonsick E, et al. Sarcopenic obesity and inflammation in the InCHIANTI study. J Appl Physiol (1985). 2007; 102: 919-25.

17. Hayashi T, Boyko EJ, Leonetti DL, et al. Visceral adiposity is an independent predictor of incident hypertension in Japanese Americans. Ann Intern Med. 2004; 140: 992-1000.

18. Mertens I, Van Gaal LF. Visceral fat as a determinant of fibrinolysis and hemostasis. Semin Vasc Med. 2005; 5: 48-55.

19. Wajchenberg BL. Subcutaneous and visceral adipose tissue: their relation to the metabolic syndrome. Endocr Rev. 2000; 21: 697-738.

20. Miyazawa-Hoshimoto S, Takahashi K, Bujo H, Hashimoto N, Saito Y. Elevated serum vascular endothelial growth factor is associated with visceral fat accumulation in human obese subjects. Diabetologia. 2003; 46: 1483-8.

21. Wong CY, O'Moore-Sullivan T, Leano R, Byrne N, Beller E, Marwick TH. Alterations of left ventricular myocardial characteristics associated with obesity. Circulation. 2004; 110: 3081-7.

22. Park J, Kim SH, Cho GY, et al. Obesity phenotype and cardiovascular changes. J Hypertens. 2011; 29: 1765-72.

23. Canepa M, Strait JB, Milaneschi $\mathrm{Y}$, et al. The relationship between visceral adiposity and left ventricular diastolic function: results from the Baltimore Longitudinal Study of Aging. Nutr Metab Cardiovasc Dis. 2013; 23: 1263-70.

24. Park J, Kim NH, Kim SH, et al. Visceral adiposity and skeletal muscle mass are independently and synergistically associated with left ventricular structure and function: the Korean Genome and Epidemiology Study. Int J Cardiol. 2014; 176: 951-5.

25. Fox CS, Gona P, Hoffmann U, et al. Pericardial fat, intrathoracic fat, and measures of left ventricular structure and function: the Framingham Heart Study. Circulation. 2009; 119: 1586-91.

26. Zhou YT, Grayburn P, Karim A, et al. Lipotoxic heart disease in obese rats: implications for human obesity. Proc Natl Acad Sci U S A. 2000; 97: 1784-9.

27. Mells JE, Fu PP, Sharma S, et al. Glp-1 analog, liraglutide, ameliorates hepatic steatosis and cardiac hypertrophy in C57BL/6 mice fed a Western diet. Am J Physiol Gastrointest Liver Physiol. 2012; 302: G225-35.

28. van der Meer RW, Rijzewijk LJ, Diamant M, et al. The ageing male heart: myocardial triglyceride content as independent predictor of diastolic function. Eur Heart J. 2008; 29. 1516-22

29. Foster MC, Hwang SJ, Larson MG, et al. Overweight, obesity, and the development of stage 3 CKD: the Framingham Heart Study. Am J Kidney Dis. 2008; 52: 39-48.

30. Hashimoto $\mathrm{Y}$, Tanaka M, Okada $\mathrm{H}$, et al. Metabolically healthy obesity and risk of incident CKD. Clin J Am Soc Nephrol. 2015; 10: 578-83.

31. Kang SH, Cho KH, Park JW, Yoon KW, Do JY. Association of visceral fat area with chronic kidney disease and metabolic syndrome risk in the general population: analysis using multi-frequency bioimpedance. Kidney Blood Press Res. 2015; 40: 223-30. 
32. Madero M, Katz R, Murphy R, et al. Comparison between Different Measures of Body Fat with Kidney Function Decline and Incident CKD. Clin J Am Soc Nephrol. 2017; 12: 893-903.

33. Odegaard JI, Chawla A. Pleiotropic actions of insulin resistance and inflammation in metabolic homeostasis. Science. 2013; 339: 172-7.

34. Aneja A, El-Atat F, McFarlane SI, Sowers JR. Hypertension and obesity. Recent Prog Horm Res. 2004; 59: 169-205.

35. Griffin KA, Bidani AK. Progression of renal disease: renoprotective specificity of renin-angiotensin system blockade. Clin J Am Soc Nephrol. 2006; 1: 1054-65. 